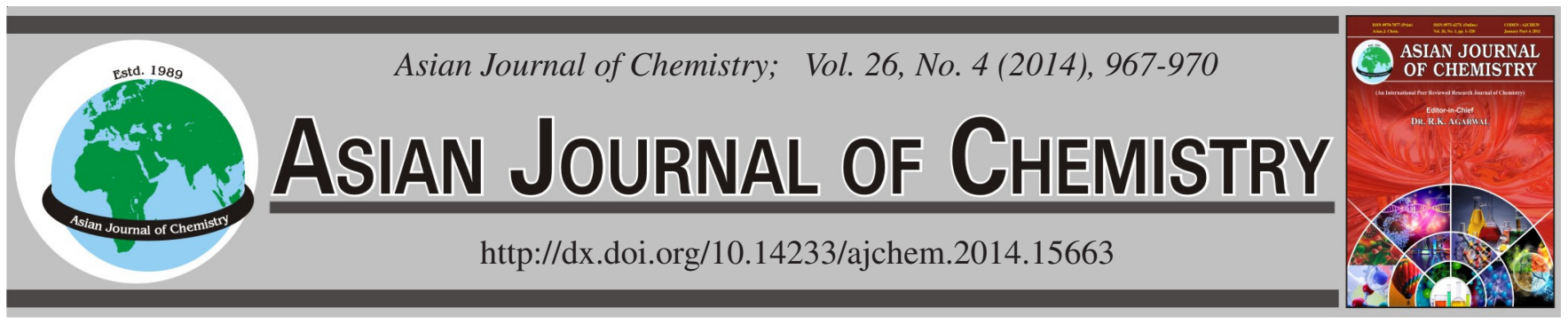

\title{
Microdialysis Coupled with Capillary Electrophoresis Method for Continuous Monitoring of Free Tramadol in Rabbit Blood
}

\author{
Li WANG
}

Department of Pharmaceutics, School of Pharmacy, Jiangsu University, Zhenjiang 212013, P.R. China

Corresponding author: Tel./Fax: +86 511 85038451; E-mail: wonjill@gmail.com

The new analytical method for the determination of protein-free tramadol in rabbit blood has been developed based on microdialysiscapillary electrophoresis method. Microdialysis probe was implanted into the ear vein of the rabbits. Separation and detection were carried out on a Beckman P/ACE 5000 equipped with UV-absorbance detector using a filter of $214 \mathrm{~nm}$. This assay was successfully applied to a pharmacokinetic study involving intravenous administration of a single dose of tramadol hydrochloride to rabbits.

Keywords: Microdialysis, Capillary electrophoresis, Tramadol, Pharmacokinetic.

ᄂ - - - - - - - - - - - - - - - - - - - - - - - - - - - -

\section{INTRODUCTION}

Tramadol is a centrally acting analgesic at opioid receptor, which appears to modify the transmission of pain impulses by inhibition of nor-epinephrine and serotonin uptake ${ }^{1}$. For the last two decades, tramadol has been used in humans to treat moderate to severe postoperative pain ${ }^{2}$. More recently, tramadol was introduced into veterinary medicine and has shown analgesic effects in mice, rats, dogs, cats, horses, parrots, alpacas, etc. ${ }^{3-9}$.

Determination of the tramadol hydrochloride have been described by several methods including high performance liquid chromatography with ultra-violet visible ${ }^{10}$, fluorescence $^{11}$, diode array ${ }^{12}$, mass spectrometry detector ${ }^{13,14}$, gas chromatography with flame ionization detection ${ }^{15,16}$ and capillary electrophoresis with UV or laser-induced native fluorescence detection $^{17-22}$. However, these methods comprise sample manipulations, extraction steps, derivatization reactions that are liable to various interferences as well as being not applicable to colored and turbid solutions. Microdialysis provides the advantage of clean samples that do not require cleanup prior to analysis. And the technique can substantially reduce the consumption of animals without withdrawal of biological fluids and involve minimal disturbance of physiological function. Moreover, multiple sites sampling provide detailed pharmacokinetic information ${ }^{23}$. The methods commonly used to couple with microdialysis are liquid chromatography. However, liquid chromatography requires a relatively large sample volume, which increases microdialysis sampling time. Capillary electrophoresis requires less sample volume and so offers an important advantage over liquid chromatography.
Accordingly, this study presents a rapid and validated capillary electrophoresis method coupled to microdialysis sampling technique to monitor free-form tramadol in rabbit blood and to study the pharmacokinetics of tramadol.

\section{EXPERIMENTAL}

Tramadol was purchased from the National Institute for the Control of Pharmaceutical and Biological Products (Beijing, China). The commercial tramadol hydrochloride was purchased from Beijing Sihuan Medicine Co. Ltd (Beijing, China). Heparin sodium was obtained from Beijing AoBoXing Universeen Bio-Tech Co. Ltd (Beijing, China). The other chemicals were of analytical grade and the water was deionized and double distilled.

Stock solution of $0.5 \mathrm{mg} / \mathrm{mL}$ tramadol was prepared in water and stored at $20{ }^{\circ} \mathrm{C}$. On the day of analysis, various tramadol working solutions were prepared through sequential dilution. Ringer's solution had the following composition: $\mathrm{NaCl}$ $145.0 \mathrm{mM}, \mathrm{KCl} 2.7 \mathrm{mM}, \mathrm{MgCl}_{2} 1.0 \mathrm{mM}, \mathrm{CaCl}_{2} 1.2 \mathrm{mM}(\mathrm{pH}$ 7.4).

Capillary electrophoresis was performed on a Beckman P/ACE 5000 equipped with UV-absorbance detector using a filter of $214 \mathrm{~nm}$. Data were acquired with the P/ACE Station software system (version 1.21). Both of these were purchased from Beckman (Beckman Coulter, Fullerton, CA, USA).

\section{General procedure}

in vitro Dialysis experiments: The microdialysis probe was placed in a beaker containing $3 \mu \mathrm{g} / \mathrm{mL}$ of tramadol in $37^{\circ} \mathrm{C}$ Ringer's solution for the purpose of determining the 
relative recovery of the probe in vitro. Dialysate was continuously pumped through the probe at $3 \mu \mathrm{L} / \mathrm{min}$. The probe was allowed to equilibrate in the tramadol solution for $50 \mathrm{~min}$ prior to collection of dialyzate samples. Dialysate samples were collected over 10 min intervals for five collection periods and were analyzed. in vitro probe recovery was calculated according to eqn. 1 .

$$
\text { Recovery }_{\text {in vitro }}=\left[\mathrm{C}_{\text {out }} / \mathrm{C}_{\mathrm{in}}\right]
$$

$\mathrm{C}_{\text {out }}$ is the concentration in the outflow solution and $\mathrm{C}_{\mathrm{in}}$ is the concentration in the medium. The in vitro recovery determination was conducted to verify normal probe function.

Microdialysis: The experiments were performed in four female, free rabbits weighing $2.5-3.5 \mathrm{~kg}$. The perfusion fluid was loaded into a $5 \mathrm{~mL}$ gas-tight glass syringe. A syringe pump was used to pump (Beijing Silugao High Technology Development Co. Ltd, China) the perfusion fluid through $60 \mathrm{~cm}$ of PTFE inlet tubing (i.d. $0.25 \mathrm{~mm}$ ) at an elevated flow rate until the entire tube was cleared of any air bubbles. The flow rate was slowed to $30 \mu \mathrm{L} / \mathrm{min}$ and the inlet tubing was connected to the microdialysis probe (molecular weight cutoff $10000 \mathrm{Da}$, Xi'an Kangpei New Technology Co., China). The dialyzate was continuously perfused through the probe at $30 \mu \mathrm{L} / \mathrm{min}$ until all air bubbles had been cleared from both the tubing and the probe. The dialyzate flow rate was then reduced to $3 \mu \mathrm{L} / \mathrm{min}$ and the probe was inserted into the edge vein of rabbits' ear. At 20 min prior to the start of the experiment, the animals were given an intravenous injection of 5000 IU of heparin sodium via the edge vein of the rabbit's ear to avoid clogging by blood coagulation during the experiments. Blanks were collected immediately following insertion of the microdialysis probe. After which the animals were received an i.v. dose (40 $\mathrm{mg} / \mathrm{kg}$ over $1 \mathrm{~min}$ ) of tramadol. Dialyzate samples were collected at 10-min intervals until tramadol was no longer detected in the dialyzate after initiation of drug infusion.

\section{Detection method}

Separation procedure: Separations were carried out with a $47 \mathrm{~cm} \times 50 \mu \mathrm{m}$ i.d. fused-silica capillary (Beckman Coulter, Fullerton, CA, USA) having an effective length of $40 \mathrm{~cm}$. On-column detection was carried out through a $3 \mathrm{~mm}$ wide window opened by removing the polyimide cover of the capillary. An $18 \mathrm{kV}$ voltage was applied, with currents typically less than 35 A. A 10 s hydrodynamic injection was made from the anodic side of the capillary by applying a $3.45 \mathrm{kPa}$ (0.5 p.s.i.) pression at the outlet of the capillary. Each day, before analyses began, the capillary was sequentially flushed for $20 \mathrm{~min}$ with $0.1 \mathrm{M} \mathrm{NaOH}$, then ultra-pure water $(7 \mathrm{~min}$ ) and finally running buffer $(7 \mathrm{~min})$. The temperature was held at $25^{\circ} \mathrm{C}$. Running electrolytes were filtered through a $0.45 \mu \mathrm{m}$ nylon membrane and degassed before use.

Method validation: Calibration samples were obtained by spiking 19 parts of blank microdialyzate with one part of working solutions of tramadol to yield seven concentrations in the range of 0.3 to $20 \mu \mathrm{g} / \mathrm{mL}$. Quality control samples were prepared as the same way. The intra- and inter-assay variabilities of tramadol were assayed (six replicates) at concentrations of $0.30,1,5,10$ and $20 \mu \mathrm{g} / \mathrm{mL}$ on the same day and on 6 sequential days, respectively. The accuracy (\% Bias) was calculated from the nominal concentrations $\left(\mathrm{C}_{\text {nom }}\right)$ and the mean value of observed concentrations $\left(\mathrm{C}_{\mathrm{obs}}\right)$ as follows:

$$
\operatorname{Bias}(\%)=\left[\left(\mathrm{C}_{\text {obs }}-\mathrm{C}_{\text {nom }}\right) /\left(\mathrm{C}_{\text {nom }}\right)\right] \times 100
$$

The precision coefficient of variation (RSD) was calculated from the observed concentrations as follows:

$\% \mathrm{RSD}=\left[\right.$ standard deviation $\left.(\mathrm{SD}) / \mathrm{C}_{\mathrm{obs}}\right] \times 100$

Accuracy (\% bias) and precision (\% RSD) values within $15 \%$ covering the range of actual experimental concentrations were considered acceptable. The limit of detection (LOD) was defined as the analyte concentration resulting in a $\mathrm{S} / \mathrm{N}$ ratio of 3:1. The limit of quantification (LOQ) was defined as the analyte concentration that could be analyzed with acceptable precision and accuracy ${ }^{24}$.

Data analysis: The dialysate concentration of tramadol in rabbit blood was calculated from the calibration curves. The free fraction of tramadol in the plasma samples was corrected for recoveries of the respective microdialysis probes using eqn. 2 .

$$
\overline{\mathrm{C}}_{\mathrm{in}}=\overline{\mathrm{C}}_{\text {out }} / \mathrm{R}_{\text {Recovery }} \text { in vitro }
$$

$\overline{\mathrm{C}}_{\mathrm{in}}$ is the substance concentration in blood and $\overline{\mathrm{C}}_{\text {out }}$ is the concentration of the dialysate. Pharmacokinetic calculations were performed on each individual animal's data utilizing the pharmacokinetic calculation software NDST-21 (China Pharmaceutical University, China).

\section{RESULTS AND DISCUSSION}

At the beginning of this study, Ringer's solution was used for microdialysis studies. However, due to the high ionic strength present in the dialysate samples and exhibit the anti-stacking in capillary electrophoresis separation, the sensitivity was poor. This problem could not be solved by dilution microdialysate with acetonitrile and water. To improve the concentration sensitivity the water was used as perfusion medium.

The starting separation buffer was adapted from the capillary electrophoresis method described by Soetebeer et $a l^{22}$ for the measurement of tramadol. Under these capillary electrophoresis conditions $(25 \mathrm{kV}, \mathrm{pH}$ 10.0, $50 \mathrm{mM}$ tetraborate buffer adjusted to $\mathrm{pH} 10$ with $\mathrm{NaOH}$ ) tramadol co-migrated with endogenous molecules contained in the microdialysates. Thereafter previously reported Tris buffer ${ }^{25}$ was used to improve the resolution. The best separation was obtained with $50 \mathrm{mM}$ Tris buffer adjusted to $\mathrm{pH} 2.5$ with phosphoric acid. A 10 s hydrodynamic injection of sample, made by applying a $3.45 \mathrm{kPa}$ (0.5 p.s.i.) pression at the outlet of the capillary, was chosen since it appeared as a good compromise between separation and sensitivity. Indeed, if the time of injection was increased, the width of all peaks increased and the analytes were less separated. Finally an adjustment of the applied voltage was needed. Voltages between 17 and $30 \mathrm{kV}$ were tested and the best separation was obtained at $18 \mathrm{kV}$ (data not shown). In summary, the separations were carried out using a running voltage of $18 \mathrm{kV}\left(25^{\circ} \mathrm{C}\right)$.

Assay validation: Typical electropherograms of standard and dialysate containing tramadol are shown in Fig. 1. Separation of tramadol from some endogenous chemicals in the blood dialysate was achieved in an optimal electrophoresis 
conditions: $50 \mathrm{mM}$ Tris ( $\mathrm{pH} 2.5$ ) buffer, $18 \mathrm{kV}$ separation voltage. Retention time of tramadol was $7.9 \mathrm{~min}$. Fig. 1A shows a standard injection of tramadol $(2 \mu \mathrm{g} / \mathrm{mL})$ and Fig. 1B shows the electropherogram of a blank blood dialyzate. None of the observed peaks interfered with the analysis of tramadol. Fig. 1(C) shows the electropherogram of a blood dialyzate sample containing tramadol $(1.1 \mu \mathrm{g} / \mathrm{mL})$ collected from a rabbit blood microdialysate $24 \mathrm{~min}$ after ciprofloxacin administration (40 mg/kg, i.v.).

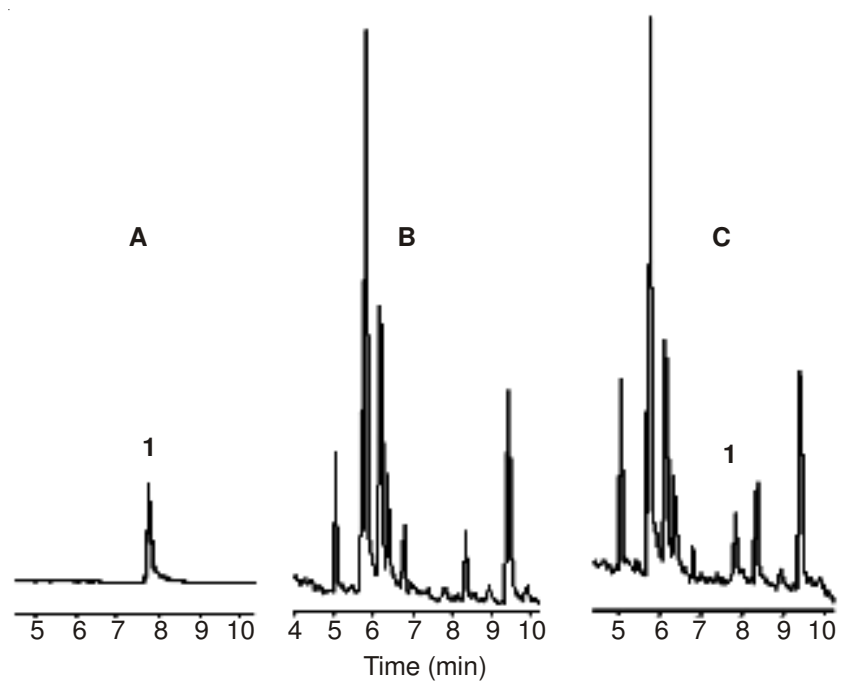

Fig. 1. Typical electropherograms of (A) standard tramadol $(2 \mu \mathrm{g} / \mathrm{mL}),(B)$ a blank blood dialyzate from the microdialysis probe prior to drug administration, and (C) a blood dialysate sample containing tramadol $(1.1 \mu \mathrm{g} / \mathrm{mL})$ collected from a rabbit blood microdialyzate $24 \mathrm{~min}$ post tramadol administration $(40 \mathrm{mg} / \mathrm{kg}$, i.v. $)$. Peak $1=$ tramadol

TABLE-1

INTRA-DAY AND INTER-DAY ACCURACY AND PRECISION OF THE CAPILLARY ELECTROPHORESIS METHOD FOR THE DETERMINATION OF TRAMADOL IN DIALYZATES

\begin{tabular}{clcc}
\hline $\begin{array}{c}\text { Nominal } \\
\text { conc. }(\mu \mathrm{g} / \mathrm{mL})\end{array}$ & $\begin{array}{c}\text { Observed* } \\
\text { conc. }(\mu \mathrm{g} / \mathrm{mL})\end{array}$ & $\begin{array}{c}\text { RSD } \\
(\%)\end{array}$ & $\begin{array}{c}\text { Accuracy } \\
(\% \text { bias })\end{array}$ \\
\hline Intra-assay $(\mathrm{n}=6)$ & & & \\
\hline 0.30 & $0.31 \pm 0.02$ & 6.4 & 3.3 \\
1.00 & $1.01 \pm 0.03$ & 3.0 & 1.0 \\
5.00 & $5.01 \pm 0.03$ & 0.6 & 0.2 \\
10.00 & $9.87 \pm 0.26$ & 2.6 & -1.3 \\
20.00 & $20.19 \pm 0.62$ & 3.1 & 1.0 \\
\hline Inter-assay $(\mathrm{n}=6)$ & & & \\
\hline 0.30 & $0.34 \pm 0.04$ & 11.8 & 13.3 \\
1.00 & $0.98 \pm 0.05$ & 5.1 & -2.0 \\
5.00 & $5.11 \pm 0.14$ & 2.7 & 2.2 \\
10.00 & $10.17 \pm 0.05$ & 0.5 & 1.7 \\
20.00 & $19.65 \pm 0.63$ & 3.2 & -1.9 \\
\hline
\end{tabular}

*Mean concentration data are expressed as rounded mean $\pm \mathrm{SD}$.

The concentration-response relationship (external standards) of the present method indicated linearity $(r=0.9986)$ over the concentration range $0.3-20 \mu \mathrm{g} / \mathrm{mL}$ for tramadol. The limit of detection (LOD) was $0.1 \mu \mathrm{g} / \mathrm{mL}$ and the limit of quantification (LOQ) was $0.3 \mu \mathrm{g} / \mathrm{mL}$, respectively. With $9 \mu \mathrm{L}$ of sample volume, these values correspond, respectively, to $2.7 \times$ $10^{-12} \mathrm{~g}$ and $0.9 \times 10^{-12} \mathrm{~g}$ of tramadol injected onto the column. Intra-day and inter-day precision (\% RSD) and accuracy (\% Bias) of tramadol fell well within the predefined limits of acceptability ( $\pm 15 \%$ ) (Table-1). The in vitro recovery $(\%)$ of tramadol in the blood microdialysis probes based on $3 \mu \mathrm{g} / \mathrm{mL}$ standard were $27.5 \% \pm 1.2 \%(\mathrm{n}=5)$.

In conclusion, the results obtained on linearity and detection limits show that the present method can be used for the determination of very low-concentrations of tramadol in microvolumes (i.e. microliter range) of biological samples.

Pharmacokinetics: Fig. 2 shows the measured concentrations versus time relationship of tramadol in rabbits' blood after tramadol (40 mg/kg, i.v.). These data have been corrected for recoveries. The distribution half-life $\left(\mathrm{T}_{1 / 2, \alpha}\right)$, elimination half-life $\left(\mathrm{T}_{1 / 2, \beta}\right)$ as well as distribution rate constant and elimination constant of tramadol in rabbit blood are listed in Table-2.

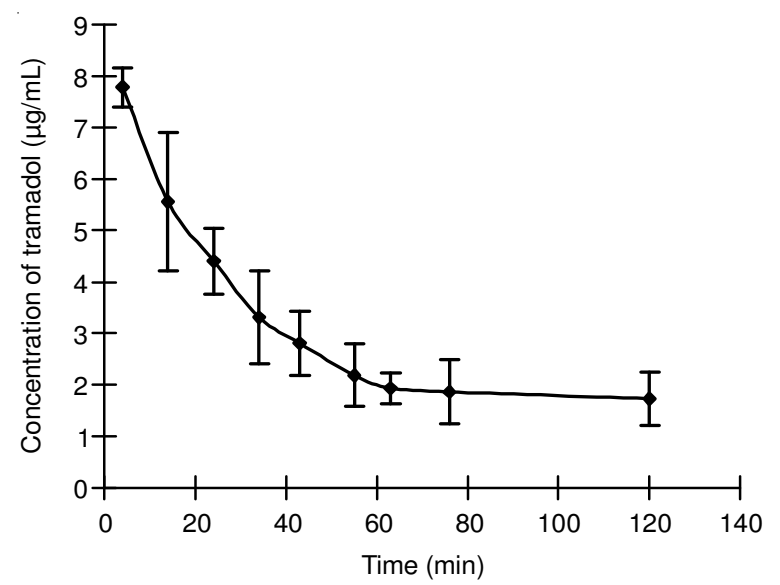

Fig. 2. Mean protein-unbound blood concentration-time profiles of tramadol $(40 \mathrm{mg} / \mathrm{kg})$. Data are presented as the mean \pm SEM $(\mathrm{n}=4)$

TABLE-2

PHARMACOKINETIC PARAMETERS IF TRAMADOL IN RABBIT BLOOD FOLLOWING $40 \mathrm{mg} / \mathrm{kg}$ INTRAVENOUS ADMINISTRATION

\begin{tabular}{cc}
\hline Parameter & Estimated $^{*}$ \\
$\mathrm{~A}(\mu \mathrm{g} / \mathrm{mL})$ & $3.8 \pm 1.3$ \\
$\mathrm{~B}(\mu \mathrm{g} / \mathrm{mL})$ & $6.5 \pm 1.6$ \\
$\alpha(1 / \mathrm{min})$ & $0.50 \pm 0.09$ \\
$\beta(1 / \mathrm{min})$ & $0.03 \pm 0.01$ \\
$\mathrm{~T}_{1 / 2, \alpha}(\mathrm{min})$ & $9.9 \pm 5.4$ \\
$\mathrm{~T}_{1 / 2, \beta}(\mathrm{min})$ & $35.8 \pm 7.5$ \\
$\mathrm{~K}_{21}(1 / \mathrm{min})$ & $0.051 \pm 0.005$ \\
$\mathrm{~K}_{10}(1 / \mathrm{min})$ & $0.025 \pm 0.009$ \\
$\mathrm{~K}_{12}(1 / \mathrm{min})$ & $0.010 \pm 0.003$ \\
$\mathrm{~V}(1 / \mathrm{kg})$ & $5.53 \pm 0.34$ \\
$\mathrm{CL}(\mathrm{mL} / \mathrm{kg} / \mathrm{min})$ & $214.5 \pm 8.4$ \\
$\mathrm{AUC}_{0-\infty}(\mathrm{min} \mu \mathrm{g} / \mathrm{mL})$ & $372.9 \pm 7.2$ \\
$\mathrm{AUC}_{0-\mathrm{t}}(\mathrm{min} \mu \mathrm{g} / \mathrm{mL})$ & $262.3 \pm 14.4$ \\
\hline
\end{tabular}

"Data are expressed as mean \pm SEM $(n=4)$.

\section{Conclusion}

The high resolving power and large peak capacity of capillary electrophoresis provide a reliable separation between endogenous substances and drugs in microdialysis samples. The present microdialysis/capillary electrophoresis method allows monitoring the extracellular concentrations of drug and the resulting biochemical changes. These data on at the site of biochemical changes may lead to a better understanding of the mechanism of action of this drug. 
The present method represents a new approach for tramadol pharmacokinetic investigation, which can be easily set-up in any pharmacology laboratory, since a commercially available capillary electrophoresis instrument is used. Besides, obtaining data in this manner can reduce the number of laboratory animals required to obtain both pharmacokinetic and pharmacodynamic information.

\section{REFERENCES}

1. M. Barann, B. Urban, U. Stamer, Z. Dorner, H. Bönisch and M. Brüss, Eur. J. Pharmacol., 531, 54 (2006).

2. L.J. Scott and C.M. Perry, Drugs, 60, 139 (2000),

3. O.N. Aydin, R.O. Ek, S. Temoçin, B. Ugur, B. Alaçam and S. Sen, Agri, 24, 49 (2012).

4. M.A. Edmondson, S.H. Duran, D.M. Boothe, A.J. Stewart and W.R. Ravis, J. Vet. Pharmacol. Ther., 35, 389 (2012).

5. S. Geelen, D.S.-M. Guzman, M.J. Souza, S. Cox, N.S. Keuler and J.R. Paul-Murphy, Am. J. Vet. Res., 74, 201 (2013).

6. S. Jiwlawat and S. Durongphongtorn, Thai. J. Vet. Med., 41, 171 (2011).

7. R.J. Paolozzi, R.N. Cassu, F.S.F. Cruz and L.R. Parrilha, Cienc. Rural, 41, 1417 (2011).

8. B.H. Pypendop, K.T. Siao and J.E. Ilkiw, Am. J. Vet. Res., 70, 1465 (2009).

9. H. Rohrbach, T. Korpivaara, U. Schatzmann and C. Spadavecchia, Vet. Anaesth. Analg., 36, 384 (2009).

10. S.H. Gan, R. Ismail, W.A. Wan Adnan and Z. Wan, J. Chromatogr. B: Analyt. Technol. Biomed. Life Sci., 772, 123 (2002).

11. H. Ebrahimzadeh, Y. Yamini, A. Sedighi and M.R. Rouini, $J$. Chromatogr. B: Analyt. Technol. Biomed. Life Sci., 863, 229 (2008).
12. A. Küçük, Y. Kadioglu and F. Celebi, J. Chromatogr. B: Analyt. Technol. Biomed. Life Sci., 816, 203 (2005).

13. N.V. de Moraes, G.R. Lauretti, M.N. Napolitano, N.R. Santos, A.L. Godoy and V.L. Lanchote, J. Chromatogr. B: Analyt. Technol. Biomed. Life Sci., 880, 140 (2012).

14. P. Li, P. Ma, Y. Wang, W. Tong, J. Wang, C. Wu and L. Liu, J. Chromatogr. B: Analyt. Technol. Biomed. Life Sci., 895-896, 10 (2012).

15. M. Liang, N. Zheng, C. Xiangyang, L. Liang, L. Yan and J. Ming, Rom. J. Leg. Med., 19, 45 (2011).

16. B.N. Patel, N. Sharma, M. Sanyal and P.S. Shrivastav, J. Pharm. Biomed. Anal., 49, 354 (2009).

17. E.C.Y. Chan and P.C. Ho, J. Chromatogr. B: Analyt. Technol. Biomed. Life Sci., 707, 287 (1998).

18. B. Kurth and G. Blaschke, Electrophoresis, 20, 555 (1999).

19. P. Lehtonen, H. Siren, I. Ojanperä and R. Kostiainen, J. Chromatogr. A, 1041, 227 (2004).

20. S. Rudaz, S. Cherkaoui, P. Dayer, S. Fanali and J.-L. Veuthey, J. Chromatogr. A, 868, 295 (2000).

21. U.B. Soetebeer, M.-O. Schierenberg, J.-G. Möller, H. Schulz, G. Grünefeld, P. Andresen, G. Blaschke and G. Ahr, J. Chromatogr. A, 895, 147 (2000).

22. U.B. Soetebeer, M.-O. Schierenberg, H. Schulz, P. Andresen and G. Blaschke, J. Chromatogr. B: Analyt. Technol. Biomed. Life Sci., 765, 3 (2001).

23. Y. Chu, X. Wang, J. Guo, W. Li, X. Ma and Y. Zhu, Eur. J. Drug Metab. Pharmacokinet., 37, 173 (2012).

24. M.D. Rockville, Food and Drug Administration, Guidance for Industry: Bioanalytical Method Validation, US Department of Health and Human Services, FDA, Center for Drug Evaluation and Research (2001). 